\title{
Are you ever too old?
}

Saswata Deb, MD, and Stephen E. Fremes, MD

See related article on pages 479-84.

By 2030, 20\% of Americans will be aged 65 years or more; cardiovascular death will rank as the leading cause of death in this group. ${ }^{1}$ PCI and CABG are the main invasive treatment modalities for ischemic heart disease; increasing age has been associated with higher risk with these procedures. ${ }^{2,3}$ Given the existing debate of which of these modalities are superior, ${ }^{4}$ along with the potential risks associated in the elderly who undergo these procedures, studies investigating such relationships in a rapidly aging population are thus important.

Benedetto and colleagues ${ }^{5}$ should be commended for addressing this important topic in this issue of the Journal, investigating the effect of age on survival after PCI or CABG. They performed a single-center, propensitymatched analysis based on 6723 patients with multivessel disease who underwent PCI $(\mathrm{n}=1097)$ or CABG $(\mathrm{n}=5626)$ from 2001 to 2013 with a mean follow-up of 5.5 years. They reported that CABG was associated with a higher overall survival especially in the late phase compared with PCI across all age groups.

There are several main strengths of this study. First, the study population was large even after matching, with 1097 subjects in each arm. Second, to address the inherent biases with observational studies, the investigators used propensity matching. This method simulates a design phase and a separate analysis phase, similar to a randomized clinical trial. Furthermore, if the match results in well-balanced groups (such as the case in this study) with respect to known confounders, then the biases associated with the treatment effects are significantly reduced. ${ }^{6}$ Third, the follow-up period was relatively long, and separating the hazard phase into early and late allowed determination of the effect of time after intervention.

A few limitations also exist in this study. The use of the matching technique eliminated many of the patients

\footnotetext{
From the Schulich Heart Centre, Sunnybrook Health Sciences Centre, University of Toronto, Toronto Ontario Institute of Health Policy Management and Evaluation, University of Toronto, Toronto, Ontario.

Disclosures: Authors have nothing to disclose with regard to commercial support.

Received for publication Oct 14, 2014; accepted for publication Oct 14, 2014; available ahead of print Nov 22, 2014.

Address for reprints: Stephen E. Fremes, MD, Schulich Heart Centre, Sunnybrook Health Sciences Centre, University of Toronto, 2075 Bayview Ave, Room H405,

Toronto, ON, Canada, M4N 3M5 (E-mail: stephen.fremes@sunnybrook.ca).

J Thorac Cardiovasc Surg 2015;149:485-6

$0022-5223 / \$ 36.00$

Copyright (c) 2015 by The American Association for Thoracic Surgery

http://dx.doi.org/10.1016/j.jtcvs.2014.10.063
}

undergoing $\mathrm{CABG}$, thereby reducing generalizability; the use of inverse probability of treatment weighting could have been an alternate option, which has an advantage of using all the data. ${ }^{6}$ Furthermore, after the matching process, there was a noticeable decrease in the proportion of left main $(28.8 \%$ to $13.3 \%)$ and 3 -vessel disease $(74.6 \%$ to $32.5 \%$ ) in the CABG group. Given that in both of these subgroups, CABG compared with PCI has been shown to be superior, ${ }^{4}$ the difference in the survival function between PCI and CABG may have been underestimated in this study. Intraoperative details, including the type of grafts used for CABG, were not present. It has been shown that arterial grafting is associated with improved survival, ${ }^{7}$ and therefore its interaction with respect to age may have had a significant role in early and late survival. Finally, the limitation of propensity score techniques, irrespective of how well the technique is performed, is the presence of unknown confounders, which is an inherent bias of any observational study.

It is also worth mentioning that as patients get older, their primary preference may be quality of life more than quantity; they may fear stroke more than survival. In this age group, social factors also become paramount, including caregiver issues after surgery; sometimes the patient may need to recover quickly to provide care for a family member. These issues can sometimes supersede clinical factors in the decision pathway of the intervention received, which is difficult to quantify analytically. Furthermore, patients in this study were deemed acceptable for surgery; therefore, conditions associated with age, including dementia, frailty, poor mobility, porcelain aorta, poor target vessels, concomitant valvular disease, and associated cancers, likely were vastly underrepresented in the surgical arm.

Despite these limitations, the authors should be commended for this well-performed study that supports the concept that $\mathrm{CABG}$ is preferred for prolongation of life in operable elderly patients. Further studies like this are encouraged to corroborate these findings; such evidence will likely affect clinical decisions and choice of coronary revascularization strategies in the elderly.

\section{References}

1. North BJ, Sinclair DA. The intersection between aging and cardiovascular disease. Circ Res. 2012;110:1097-108.

2. Weisel RD, Nussmeier N, Newman MF, Pearl RG, Wechsler AS, Ambrosio G et al. Predictors of contemporary coronary artery bypass grafting outcomes. J Thorac Cardiovasc Surg. August 14, 2014 [Epub ahead of print].

3. Johnman C, Oldroyd KG, Mackay DF, Slack R, Pell AC, Flapan AD, et al Percutaneous coronary intervention in the elderly: changes in case-mix and periprocedural outcomes in 31,758 patients treated between 2000 and 2007. Circ Cardiovasc Interv. 2010;3:341-5. 
4. Deb S, Wijeysundera HC, Ko DT, Tsubota H, Hill S, Fremes SE. Coronary artery bypass graft surgery vs percutaneous interventions in coronary revascularization: a systematic review. JAMA. 2013;310:2086-95.

5. Benedetto U, Amrani M, Toufan B, Gaer J, De Robertis F, Smith RD, et al. Survival probability loss from percutaneous coronary intervention compared with coronary artery bypass grafting across individual patient's age. J Thorac Cardiovasc Surg. 2015;149:479-84.
6. Austin PC. An introduction to propensity score methods for reducing the effects of confounding in observational studies. Multivariate Behav Res. 2011;46: 399-424.

7. Buxton BF, Shi WY, Tatoulis J, Fuller JA, Rosalion A, Hayward PA. Total arterial revascularization with internal thoracic and radial artery grafts in triple-vessel coronary artery disease is associated with improved survival. J Thorac Cardiovasc Surg. 2014;148:1238-44. 